\title{
Botulinum Toxin Type A for Diabetic Peripheral Neuropathy Pain: A Systematic Review and Meta-Analysis
}

\author{
Chengbing Wang' \\ Qian Zhang ${ }^{2}$ \\ Renjie Wang ${ }^{3}$ \\ Lei $\mathrm{Xu}{ }^{\prime}$
}

'Department of Neurology, China-Japan Union Hospital of Jilin University, Changchun, Jilin, People's Republic of China; ${ }^{2}$ Department of Cardiology, China-Japan Union Hospital of Jilin University, Changchun, Jilin, People's Republic of China; ${ }^{3}$ Department of Nuclear Medicine, China-Japan Union Hospital of Jilin University, Changchun, jilin, People's Republic of China
Correspondence: Lei $\mathrm{Xu}$

Department of Neurology, China-Japan Union Hospital of Jilin University, Xiantai Street No. 126, Changchun, Jilin, People's Republic of China

Tel +8618186818612

Fax +8684995916

Email xuleijlu@jlu.edu.cn

Renjie Wang

Department of Nuclear Medicine, ChinaJapan Union Hospital of Jilin University,

Xiantai Street No. 126, Changchun, Jilin,

People's Republic of China

Tel +86 I8678755I35

Fax +8684995916

Email wangrenjie@jlu.edu.cn
Purpose: Botulinum toxin type A (BTX-A) has been proposed as a treatment for painful diabetic peripheral neuropathy (DPN). This systematic review and meta-analysis aimed to assess the effect and safety of BTX-A for treating DPN pain.

Methods: PubMed, Embase, and Cochrane Library were searched for relevant articles published up to July 7, 2021. Randomized clinical trials (RCTs) were included if they were related to the treatment of DPN pain with BTX-A. The primary outcome was the change in intensity of pain and secondary outcomes were adverse effects and changes in sleep and life quality.

Results: A total of four studies, comprising 231 patients, were included in our systematic review. BTX-A treatment induced a greater reduction in the visual analog scale score (mean difference $=-2.52,95 \%$ confidence interval $[\mathrm{CI}][-3.06,-1.99], p<0.001)$ than did the placebo treatment, with no significant heterogeneity between studies $\left(\mathrm{I}^{2}=0\right)$. BTX-A treatment improved several neuropathy pain scale items (eg, hot sensation, sensitive sensation, unpleasant sensation, deep pain, and surface pain) significantly more than with placebo treatment ( $p<0.05$ for all). There was no significant difference in adverse effect (relative risk $=1.00,95 \%$ CI [0.97, 1.03], $p=0.89$ ).

Conclusion: Intradermal BTX-A injection was shown to be effective and safe in relieving DPN pain. Further larger scale and well-designed RCTs are needed.

Keywords: botulinum toxin, diabetes, peripheral neuropathic pain, systematic review

\section{Introduction}

Diabetic peripheral neuropathy (DPN) is characterized by pain, paresthesia, and sensory disturbances, which are mainly caused by an impaired somatosensory system. ${ }^{1}$ DPN pain affects patients' quality of life to the degree that sleep disorder and mental illnesses, such as anxiety and depression, may occur. ${ }^{2}$ Diabetes is a leading cause of DPN. According to previous reports, the prevalence of painful DPN is $10-26 \%$ in diabetic patients and is strongly associated with the high incidence of diabetes. ${ }^{3}$ The number of patients that experience painful DPN is on the rise, and there is an urgent need to develop an effective treatment.

Numerous drugs, including antidepressants, carbamazepine, gabapentin, and opioids have been used to treat DPN. ${ }^{4}$ Recently, topical medications have been introduced, such as lidocaine patches and high-dose capsaicin. ${ }^{5}$ However, due to the lack of long-lasting analgesic effects and side effects, these drugs are often ineffective or not well tolerated. ${ }^{6}$ Botulin toxin type A (BTX-A) is an effective 
neurotoxin that is usually used to treat dystonia, muscle hyperactivity, and glandular hyperactivity. However, animal model studies have revealed promising results that suggest that BTX-A may induce long-lasting analgesic effects for painful DPN in humans. ${ }^{7,8}$ The mechanisms by which the botulin toxin alleviates neuropathic pain in animals include: (1) blocking the release of peripheral nerve ending pain mediators (eg, glutamate, substance P) $;^{9}$ (2) reducing local inflammatory reactions around nerve endings; ${ }^{10}$ (3) sodium ion channel inactivation; ${ }^{11}$ (4) inhibition of muscle spindle discharge, ${ }^{12}$ and (5) inhibition of sympathetic nerve transmission. ${ }^{13}$ The last two mechanisms increase the sensitivity of the central nervous system.

BTX-A has been proposed as a treatment for painful DPN. However, the efficacy and safety of BTX-A for treating DPN pain require careful evaluation. The purpose of this systematic review and meta-analysis was to provide a better understanding of the effectiveness and safety of BTX-A for treating DPN pain.

\section{Materials and Methods}

This systematic review and meta-analysis was registered in PROSPERO (number CRD42021229129) and is reported in accordance with the Preferred Reporting Items for Systematic Reviews and Meta-Analyses (PRISMA) Statement. ${ }^{14}$

\section{Search Strategy}

PubMed, Embase, and Cochrane Library were searched for relevant randomized clinical trials (RCTs) published up to July 7, 2021. No language restrictions were imposed. The following combined terms and synonyms were searched: "diabetic neuropathies," "botulinum toxin type A," and "botulinum toxins". The complete search strategy is presented in Supplementary Table S1. Reference lists of included studies were also screened to supplement the search.

\section{Study Selection}

Studies that met the following inclusion criteria were selected: (a) subjects were patients with DPN (symmetrical distal sensory and motor polyneuropathy), previously diagnosed using the douleur neuropathique 4 questionnaire and nerve conduction velocity examinations; (b) the experimental group received botulinum toxin injection, and the control group was treated with placebo; (c) the outcomes were intensity of pain, adverse effects, quality of sleep, and quality of life; and (d) the study design was a randomized double-blind placebo-controlled clinical trial.

Reviews, conference abstracts, case reports, repeatedly published or data-overlapping studies, animal studies, and unrelated articles were excluded.

\section{Primary and Secondary Outcomes}

The primary outcome was change in pain intensity measured using the visual analog scale (VAS) or neuropathy pain scale (NPS) between baseline and follow-up; the intensity of pain was rated from 0 , denoting no pain, to 10 , indicating "the worst pain imaginable."

The secondary outcomes were as follows: number of patients with any adverse effects, change in score of the Pittsburgh Sleep Quality Index (PSQI), and change in score of the Short Form-36 (SF-36) quality-of-life questionnaire between baseline and follow-up.

\section{Data Extraction and Quality Assessment}

Two authors extracted and cross-checked the data independently, and all disagreements were resolved through discussion. The following data were collected: first author's name, publication year, country, total number of patients, sex, age, design, type of botulinum toxins, dosage, route of administration, injection sites, trial duration, means and standard deviations (SDs) of the VAS, NPS, PSQI, and SF-36 scores, and number of patients with any adverse effects. The Cochrane Risk of Bias assessment tool was used to evaluate the quality of the studies. $^{15}$

\section{Statistical Analysis}

Only the outcomes at the closest time point between studies were analyzed. We analyzed changes in VAS, NPS, PSQI, and SF-36 scores as continuous variables and reported the mean differences (MDs) between before and after the interventions. Missing SDs of change scores were imputed using the approach proposed by the Cochrane Handbook. ${ }^{16}$ For analyses of the proportion of patients who had any adverse effects, we calculated the overall relative risk (RR). A random-effects model was used to calculate the pooled estimates of the MDs of the change in the scores between the intervention groups. We also calculated pooled estimates of the RR of the categorical outcomes using a random-effects model. A $p$-value $<0.05$ was considered statistically significant.

For crossover studies, we assumed that the carryover effect was negligible, and therefore, we analyzed paired 
results. We also conducted a sensitivity analysis by excluding crossover studies. For multi-arm studies, we combined the results of single-foot and double-foot injections. In addition, a subgroup analysis was performed according to single-foot or double-foot injections.

An $\mathrm{I}^{2}$-test was used to evaluate the heterogeneity between studies, with $\mathrm{I}^{2}>50 \%$ indicating moderate-tohigh heterogeneity. ${ }^{17}$ The causes of heterogeneity were found using subgroup analyses. A funnel plot was generated to detect publication bias, and funnel plot asymmetry was assessed using Egger's test, with a $p$-value < 0.05 indicating significant publication bias. ${ }^{18}$ All statistical analyses were performed using Revman version 5.3

\section{Results}

\section{Study Selection and Characteristics}

A total of 263 articles were identified through database searching, of which four (including 231 patients) were included in our systematic review (Figure 1). The four studies were all RCTs. ${ }^{19-22}$ The study by Yuan et al was a crossover RCT, and the study by Taheri et al was a multi-arm RCT, which compared the efficacy between the single-foot injection and double-foot injection groups. The average age was 57 years, and females accounted for $58.9 \%$ of the total study population. Trial durations ranged from 3 to 12 weeks. The route of administration of all four studies was intradermal. The injection sites were identical in three studies, which used a $3 \times 4$ grid that was equally spaced on the dorsum of each foot. ${ }^{19-21}$ One

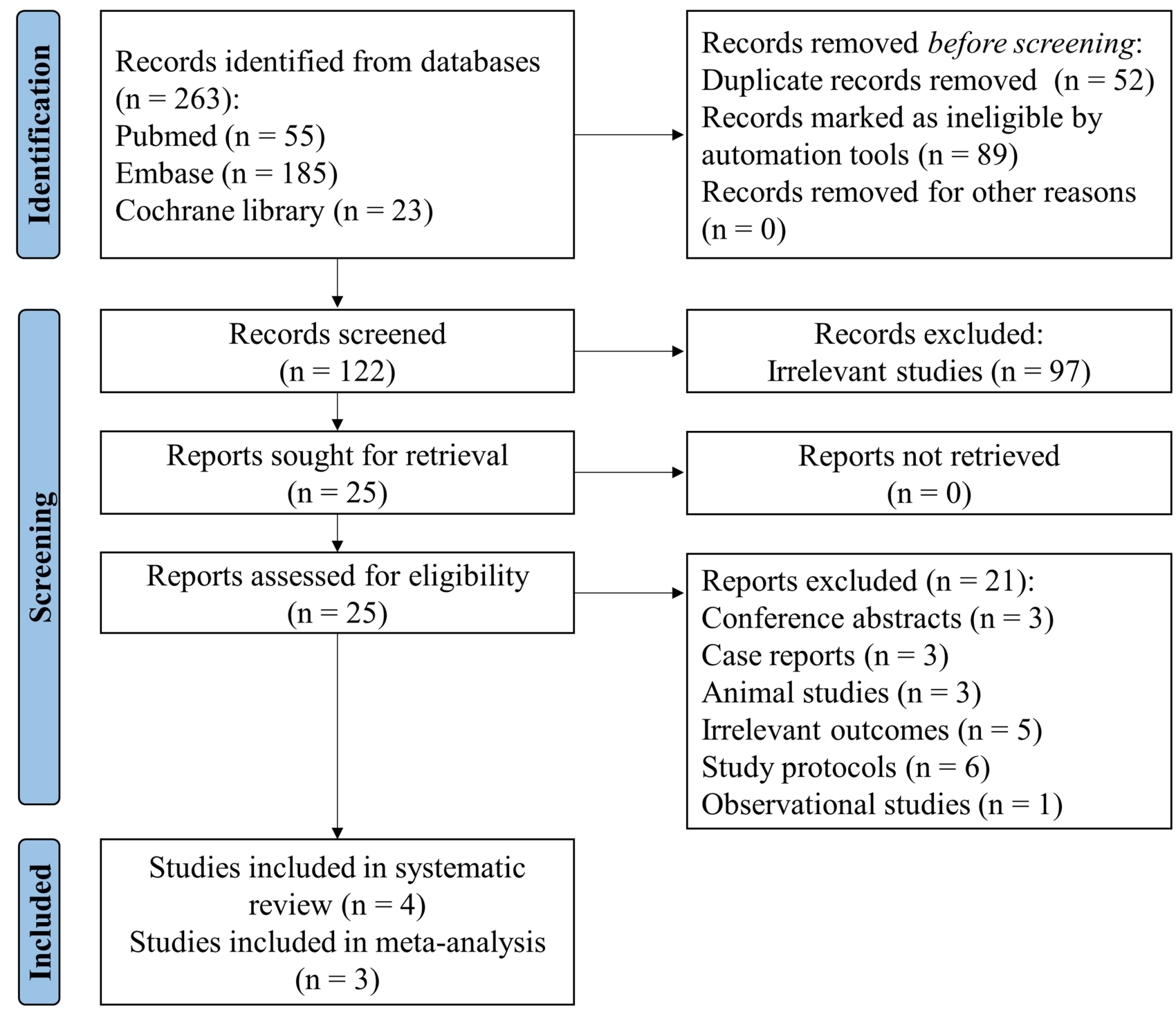

Figure I Study selection flow diagram. 
Table I Characteristics of Included Studies

\begin{tabular}{|c|c|c|c|c|c|c|c|c|}
\hline \multirow{2}{*}{$\begin{array}{l}\text { Author } \\
\text { (Year), } \\
\text { Country }\end{array}$} & \multirow{2}{*}{$\begin{array}{l}\text { Age, } \\
\text { M/F } \\
\text { (n) }\end{array}$} & \multirow[t]{2}{*}{ Design } & \multicolumn{4}{|c|}{ Interventions } & \multicolumn{2}{|c|}{ Outcomes } \\
\hline & & & Toxin & Route & Dosage & Injection Sites & Measures & $\begin{array}{l}\text { Time- } \\
\text { Points }\end{array}$ \\
\hline $\begin{array}{l}\text { Yuan et al } \\
(2009)^{19} \\
\text { Taiwan, } \\
\text { China }\end{array}$ & $\begin{array}{l}65.6 \pm \\
9.2,6 / \\
12 \\
(18)\end{array}$ & $\begin{array}{l}\text { Double- } \\
\text { blind } \\
\text { crossover } \\
\text { RCT }\end{array}$ & $\begin{array}{l}\text { BoNT/ } \\
\text { A vs } \\
\text { placebo }\end{array}$ & Intradermal & $\begin{array}{l}50 \text { units of BoNT/A in } \\
1.2 \mathrm{~mL} 0.9 \% \text { saline } \\
\text { into each foot. }\end{array}$ & $\begin{array}{l}\text { A grid distribution pattern of } \\
12(3 \times 4) \text { sites across the } \\
\text { dorsum of both feet. }\end{array}$ & $\begin{array}{l}\text { VAS, PSQI, } \\
\text { and SF-36 }\end{array}$ & $\begin{array}{l}\mathrm{I}, 4,8 \text {, and } \\
12 \text { weeks } \\
\text { after } \\
\text { injection }\end{array}$ \\
\hline $\begin{array}{l}\text { Ghasemi } \\
\text { et al } \\
(20 \mid 4)^{20} \\
\text { Iran }\end{array}$ & $\begin{array}{l}61.0 \pm \\
9.8 \\
22 / 18 \\
(40)\end{array}$ & $\begin{array}{l}\text { Double- } \\
\text { blind RCT }\end{array}$ & $\begin{array}{l}\text { BTX-A } \\
\text { vs } \\
\text { placebo }\end{array}$ & Intradermal & $\begin{array}{l}100 \text { units of BTX-A in } \\
0.9 \% \text { saline into one } \\
\text { foot. }\end{array}$ & $\begin{array}{l}\text { A grid distribution pattern of } \\
12(3 \times 4) \text { sites across the } \\
\text { dorsum of a single foot. }\end{array}$ & $\begin{array}{l}\text { VAS and } \\
\text { NPS }\end{array}$ & $\begin{array}{l}3 \text { weeks } \\
\text { after } \\
\text { injection }\end{array}$ \\
\hline $\begin{array}{l}\text { Salehi et al } \\
(2019)^{21} \\
\text { Iran }\end{array}$ & $\begin{array}{l}57.5 \pm \\
6.4 \\
12 / 20 \\
(32)\end{array}$ & $\begin{array}{l}\text { Double- } \\
\text { blind RCT }\end{array}$ & $\begin{array}{l}\text { BTX-A } \\
\text { vs } \\
\text { placebo }\end{array}$ & Intradermal & $\begin{array}{l}100 \text { units of BTX-A in } \\
1.2 \mathrm{~mL} \text { normal saline } \\
\text { into each foot. }\end{array}$ & $\begin{array}{l}\text { A grid distribution pattern of } \\
12(3 \times 4) \text { points on the foot } \\
\text { surface. }\end{array}$ & $\begin{array}{l}\text { VAS, NPS, } \\
\text { PSQI, and } \\
\text { SF-36 }\end{array}$ & $\begin{array}{l}\mathrm{I}, 4,8 \text {, and } \\
\text { I } 2 \text { weeks } \\
\text { after } \\
\text { injection }\end{array}$ \\
\hline $\begin{array}{l}\text { Taheri } \\
\text { et al } \\
(2020)^{22} \\
\text { Iran }\end{array}$ & $\begin{array}{l}55.2 \pm \\
7.4 \\
55 / 86 \\
(141)\end{array}$ & $\begin{array}{l}\text { Double- } \\
\text { blind } \\
\text { multi-arm } \\
\text { RCT }\end{array}$ & $\begin{array}{l}\text { BTX-A } \\
\text { vs } \\
\text { placebo }\end{array}$ & Intradermal & $\begin{array}{l}\text { DI: } 150 \text { units of BTX- } \\
A \text { in } 2 \mathrm{~mL} 0.9 \% \text { saline } \\
\text { into the right foot. } \\
\text { D2: } 150 \text { units of BTX- } \\
\text { A in } 4 \mathrm{~mL} 0.9 \% \text { saline } \\
\text { into both feet. }\end{array}$ & $\begin{array}{l}\text { A grid distribution pattern of } \\
20(5 \times 4) \text { points in the sole } \\
\text { of the foot. }\end{array}$ & $\begin{array}{l}\text { VAS and } \\
\text { NPS }\end{array}$ & $\begin{array}{l}4 \text { weeks } \\
\text { after } \\
\text { injection }\end{array}$ \\
\hline
\end{tabular}

Abbreviations: M, male; F, female; RCT, randomized clinical trial; BoNT/A and BTX-A, botulinum toxin type A; DI, injection in a single foot; D2, injection in both feet; VAS, visual analog scale; NPS, neuropathy pain scale; PSQI, Pittsburgh Sleep Quality Index; SF-36, Short Form-36 quality-of-life questionnaire.

study used a $5 \times 4$ grid in the sole of the foot. ${ }^{22}$ All included studies used BTX-A for the injections. The dosage range of BTX-A was between 50 and 150 units in each foot. The characteristics of the included studies are shown in Table 1.

\section{Risk of Bias}

The quality assessment of the included studies is shown in Figure 2. The study by Yuan et al was funded by industry and did not explain how the random sequence was generated; however, they reported that the patients were assigned randomly. ${ }^{19}$ Only one study used proper allocation concealment to ensure that the trial investigators and participants were masked to treatment allocation. ${ }^{22}$ The funnel plot and Egger's test $(p=0.277)$ suggested that the studies had no significant publication bias (Figure 3). The overall risk of bias across all included studies was low.

\section{Primary Outcome}

Three studies assessed the change in VAS score after injection. ${ }^{19,20,22}$ We analyzed the data at 3 and 4 weeks. The pooled analysis of these studies showed a significantly greater reduction in VAS score with BTX-A treatment compared with placebo treatment $(\mathrm{MD}=-2.52,95 \%$ confidence interval [CI] [-3.06, -1.99], $p<0.001)$, with no significant heterogeneity between studies ( $\mathrm{I}^{2}=0$; Figure 4$)$. The sensitivity analysis showed that the reduction in VAS score with BTX-A treatment remained significant after excluding the crossover study ( $\mathrm{MD}=-2.56,95 \%$ CI $[-3.24,-1.87], p<$ 0.001; Supplementary Figure S1). The subgroup analysis indicated that both BTX-A single-foot and double-foot injections decreased the VAS score, and there was no significant difference between the two modes of administration in regard to the efficacy of BTX-A treatment (Figure 5).

Two studies assessed the change in NPS score after injection. ${ }^{20,22}$ Pooling the data of these studies showed that hot sensation, sensitive sensation, unpleasant sensation, deep pain, and surface pain improved significantly more after BTX-A treatment than after placebo treatment ( $p<0.05$ for all), except for sharp, dull, and cold sensations (Figure 6).

\section{Secondary Outcome}

One study reported one adverse event of mild local skin infection at the injection site; however, there was no significant difference $(\mathrm{RR}=1.00,95 \% \mathrm{CI}[0.97,1.03], p=$ 0.89; Figure 7). 


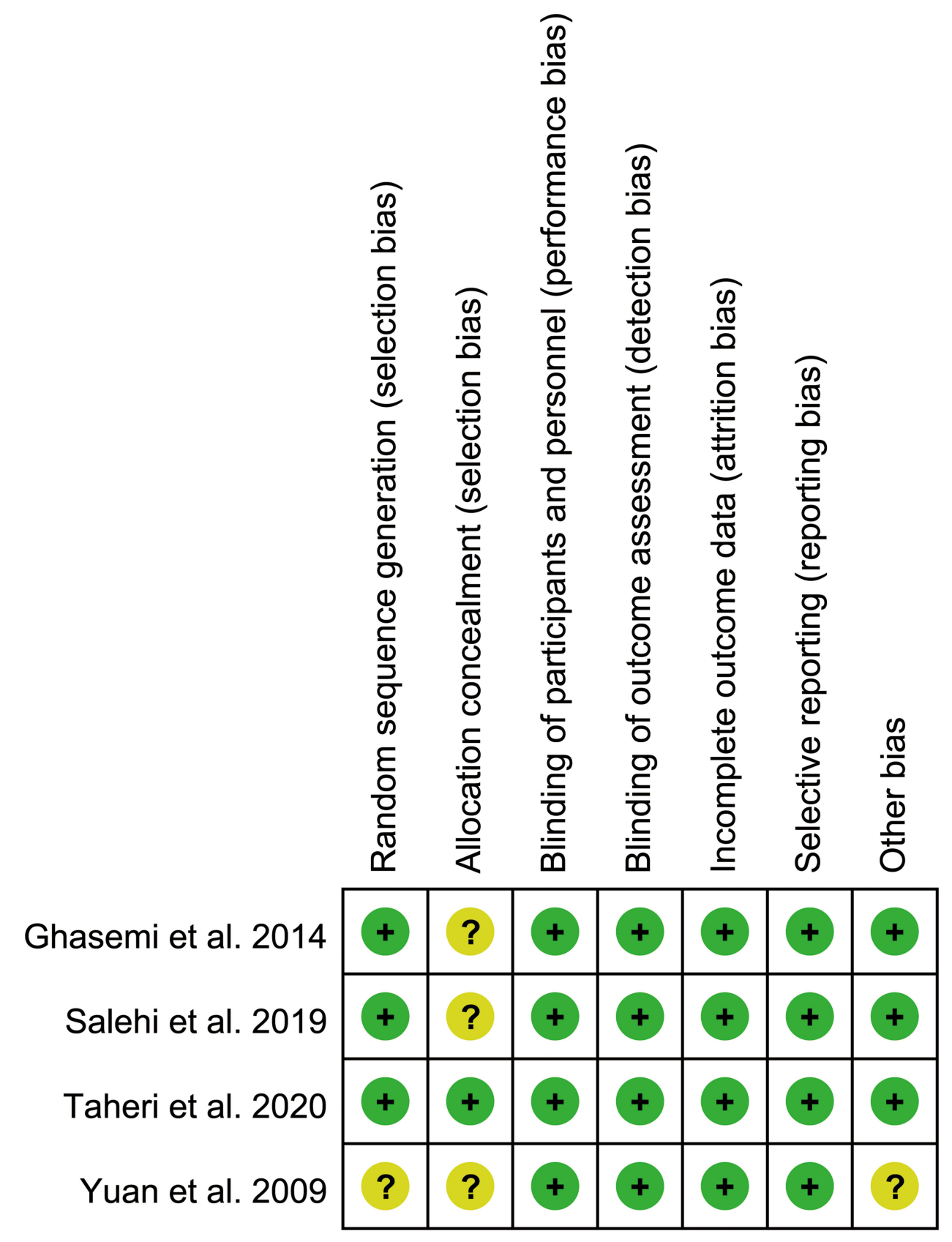

Figure 2 Quality assessment.

Two studies assessed the change in PSQI score after injection. One study suggested that BTX-A treatment provided greater improvement in sleep quality transiently at only 4 weeks after injection than after placebo treatment. ${ }^{19}$ Another study that measured mean PSQI score over time showed that BTX-A treatment improved sleep quality within 12 weeks. ${ }^{21}$

Two studies assessed the change in SF-36 score after injection. One study showed that BTX-A treatment failed to improve life quality in the physical and mental domains. ${ }^{19}$
Another study reported that BTX-A treatment did not improve the mental domain of life quality but improved the mean score of the physical domain within 12 weeks. ${ }^{21}$

\section{Discussion}

This systematic review and meta-analysis suggested that BTX-A treatment in patients with DPN pain decreases VAS score and some NPS items (including hot sensation, sensitive sensation, unpleasant sensation, deep pain, and surface pain) significantly more than with placebo 


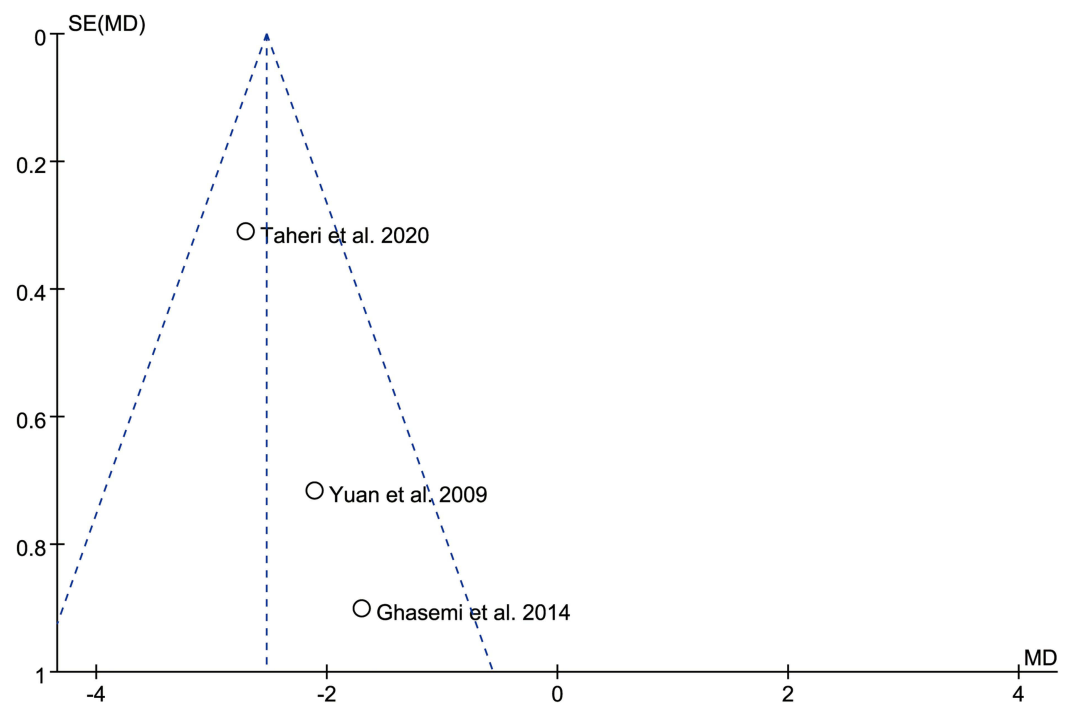

Figure 3 Funnel plot.

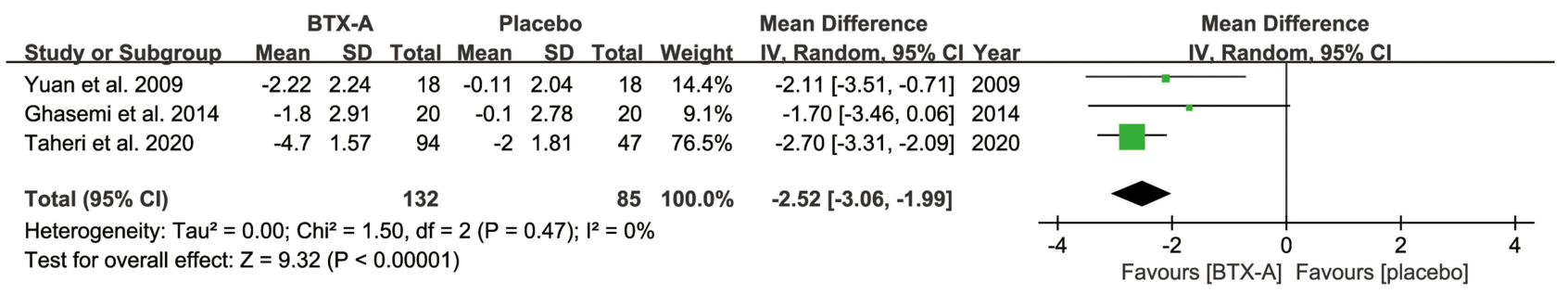

Figure 4 Meta-analysis of change in visual analog scale (VAS) score following treatment with botulinum toxin type A (BTX-A) for diabetic peripheral neuropathy (DPN) pain.

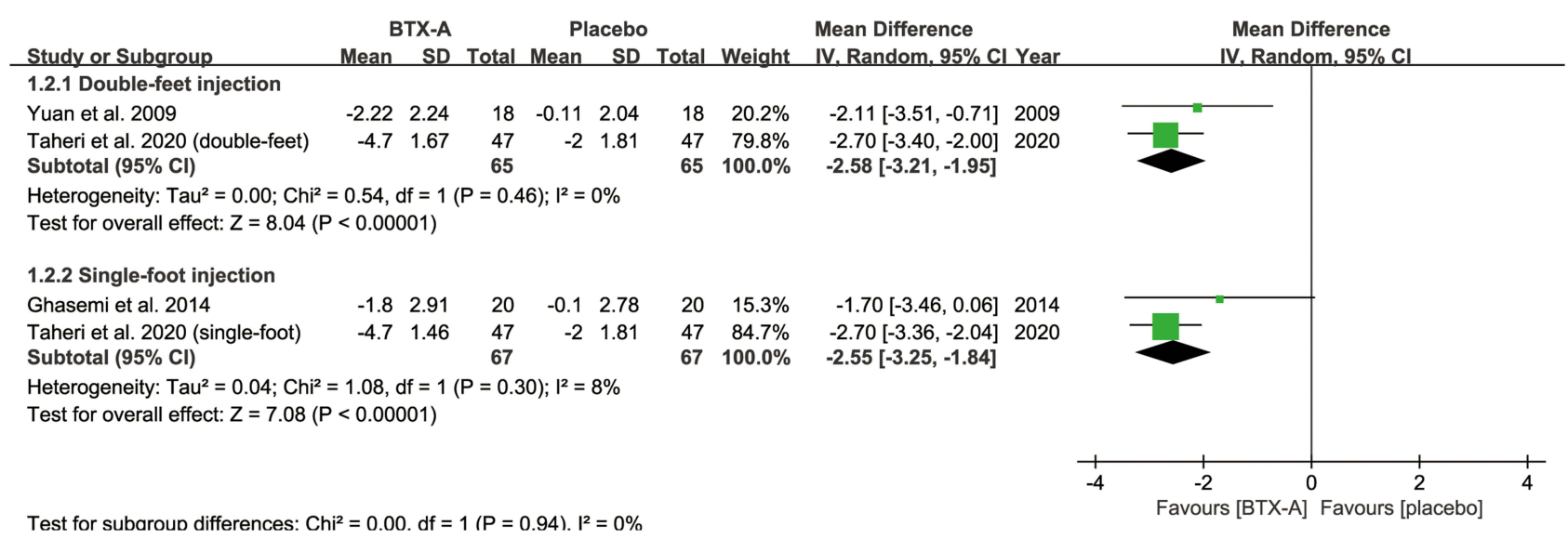

Figure 5 Subgroup analysis of change in visual analog scale (VAS) score following treatment with botulinum toxin type A (BTX-A) for diabetic peripheral neuropathy (DPN) pain.

treatment, with almost no serious adverse events. Thus, these findings lend support to BTX-A injection as an effective and safe treatment for relieving DPN pain.

Improvements in sleep and life quality in DPN patients are also a major concern. Our systematic review showed a trend toward BTX-A treatment improving sleep and life quality. The study by Yuan et al suggested that BTX-A treatment improves sleep quality transiently, but does not improve life quality. ${ }^{19}$ However, the study by Salehi et al indicated that BTX-A treatment improves average sleep and life quality within the follow-up period. ${ }^{21}$ The difference in outcomes may be due to the dose-effect; 50 units 


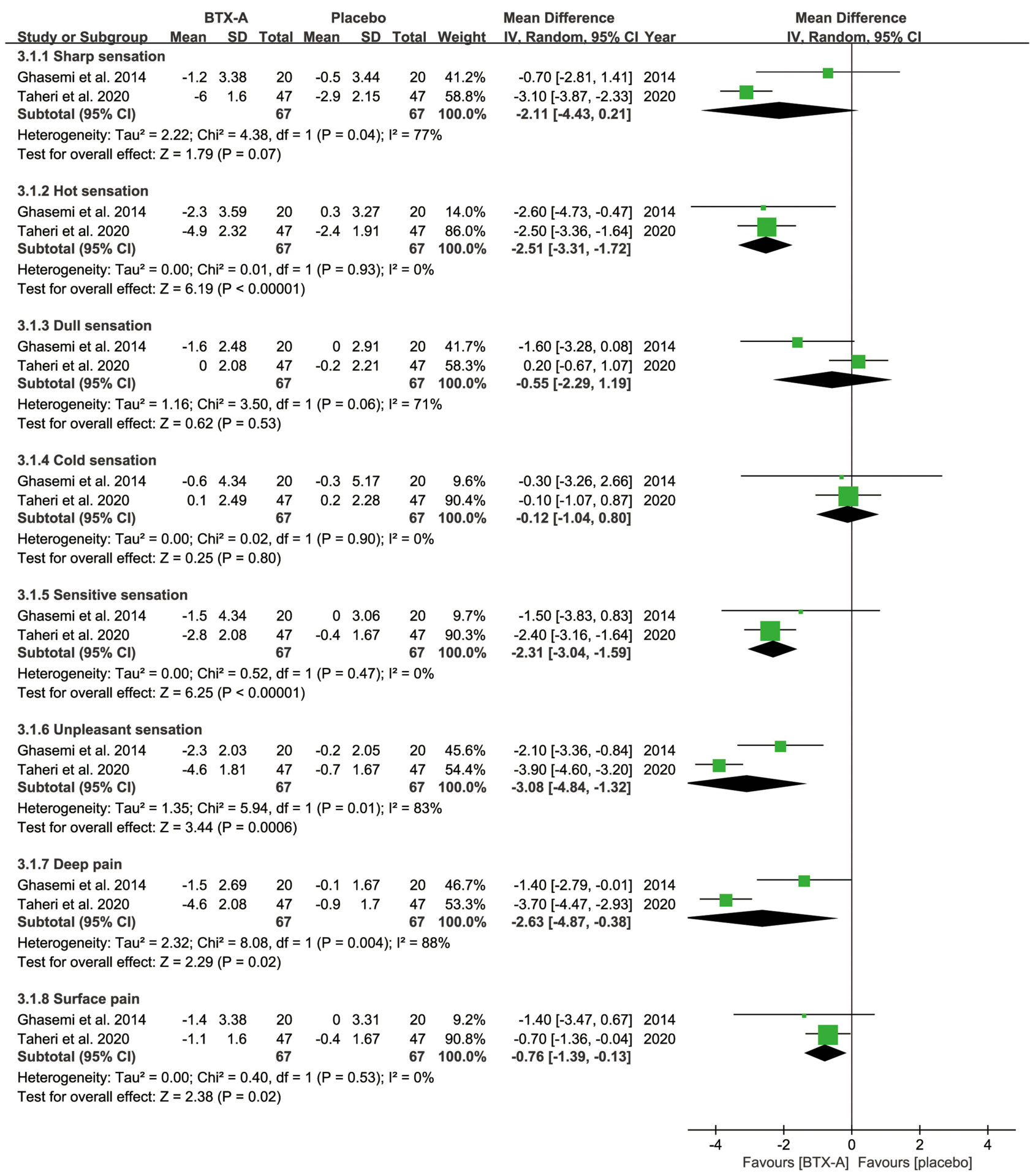

Figure 6 Meta-analysis of change in neuropathy pain scale (NPS) score following treatment with botulinum toxin type A (BTX-A) for diabetic peripheral neuropathy (DPN) pain.

of BTX-A were administered in the study by Yuan et al, whereas 100 units of BTX-A were administered in the study by Salehi et al. Therefore, the efficacy of BTX-A for improving sleep and life quality warrants further investigation.
A crossover study was included in our meta-analysis. ${ }^{19}$ This crossover study did not include an intervening washout period; nevertheless, we considered the carryover effect would have been negligible based on the long duration of each period (12 weeks). Thus, we used paired data 


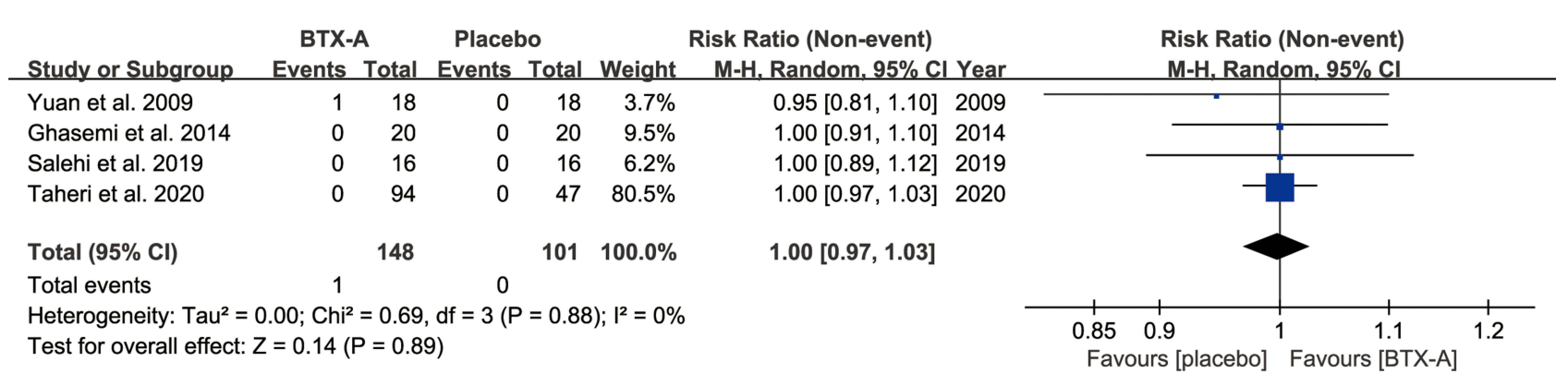

Figure 7 Meta-analysis of the occurrence of adverse effects following treatment with botulinum toxin type A (BTX-A) for diabetic peripheral neuropathy (DPN) pain.

of this crossover study to calculate the pooled results. In addition, the sensitivity analysis indicated that the crossover study did not present significant bias for the pooled results.

The administration mode of single-foot or double-foot injection remains controversial. The subgroup analysis showed that both single-foot and double-foot injections decrease the intensity of pain, which may be due to the central effects of BTX-A. BTX-A is transported to the central nervous system via retrograde axonal transport after injection at peripheral sites. ${ }^{23}$ The single-foot injection should be adopted in future practice to reduce the unpleasantness of the injection. Moreover, an administration method of "following the pain" should be considered in future research.

Regarding the route of administration, all included studies used intradermal injection. BTX-A is usually administrated intramuscularly for focal spasticity or dystonia. However, given the scope of the painful area and the security of injection, intradermal injection is more favorable than intramuscular injection for DPN pain. In the included studies, effectiveness peaked 4 weeks after the injection and lasted for at least 12 weeks. In addition, the dose of BTX-A varied between studies, with 50-150 units of BTX-A dissolved in $1.2-4 \mathrm{~mL}$ of normal saline per foot.

A limitation of this systematic review is the small number of included studies and the small sample sizes of the studies. Second, the effectiveness of multiple BTX-A injections and the long-term durability remain unclear. Finally, the optimal dosage of BTX-A for DPN pain requires further investigation.

\section{Conclusion}

Intradermal BTX-A injection is a promising alternative treatment for DPN pain. Further larger scale and welldesigned RCTs are needed.

\section{Abbreviations}

BTX-A, botulinum toxin type A; DPN, diabetic peripheral neuropathy; RCT, randomized clinical trial; VAS, visual analog scale; NPS, neuropathy pain scale; PSQI, the Pittsburgh Sleep Quality Index; SF-36, the Short Form36 quality-of-life questionnaire; SD, standard deviation; $\mathrm{MD}$, mean differences; RR, relative risk; $\mathrm{CI}$, confidence interval.

\section{Data Sharing Statement}

Data are available on reasonable request by qualified investigators to the corresponding author.

\section{Consent for Publication}

The authors confirm that all of the contents in this review can be published.

\section{Funding}

This review did not receive any funding.

\section{Disclosure}

The authors report no conflicts of interest in this work.

\section{References}

1. Tankisi H, Pugdahl K, Fuglsang-Frederiksen A, et al. Pathophysiology inferred from electrodiagnostic nerve tests and classification of polyneuropathies. Suggested guidelines. Clin Neurophysiol. 2005;116 (7):1571-1580. doi:10.1016/j.clinph.2005.04.003

2. Davies M, Brophy S, Williams R, Taylor A. The prevalence, severity, and impact of painful diabetic peripheral neuropathy in type 2 diabetes. Diabetes Care. 2006;29(7):1518-1522. doi:10.2337/dc052228

3. Boulton AJ, Kirsner RS, Vileikyte L. Clinical practice. Neuropathic diabetic foot ulcers. $N$ Engl J Med. 2004;351(1):48-55. doi:10.1056/ NEJMcp032966

4. Griebeler ML, Morey-Vargas OL, Brito JP, et al. Pharmacologic interventions for painful diabetic neuropathy: an umbrella systematic review and comparative effectiveness network meta-analysis. Ann Intern Med. 2014;161(9):639-649. doi:10.7326/M14-0511 
5. Rosenberg CJ, Watson JC. Treatment of painful diabetic peripheral neuropathy. Prosthet Orthot Int. 2015;39(1):17-28. doi:10.1177/ 0309364614542266

6. Dworkin RH, O'Connor AB, Backonja M, et al. Pharmacologic management of neuropathic pain: evidence-based recommendations. Pain. 2007;132(3):237-251. doi:10.1016/j.pain.2007.08.033

7. Ranoux D, Attal N, Morain F, Bouhassira D. Botulinum toxin type A induces direct analgesic effects in chronic neuropathic pain. Ann Neurol. 2008;64(3):274-283. doi:10.1002/ana.21427

8. Sim WS. Application of botulinum toxin in pain management. Korean J Pain. 2011;24(1):1-6. doi:10.3344/kjp.2011.24.1.1

9. Meng J, Wang J, Lawrence G, Dolly JO. Synaptobrevin I mediates exocytosis of CGRP from sensory neurons and inhibition by botulinum toxins reflects their anti-nociceptive potential. J Cell Sci. 2007;120(16):2864-2874. doi:10.1242/jcs.012211

10. Cui M, Khanijou S, Rubino J, Aoki KR. Subcutaneous administration of botulinum toxin A reduces formalin-induced pain. Pain. 2004;107 (1-2):125-133. doi:10.1016/j.pain.2003.10.008

11. Shin MC, Wakita M, Xie DJ, et al. Inhibition of membrane $\mathrm{Na}+$ channels by A type botulinum toxin at femtomolar concentrations in central and peripheral neurons. J Pharmacol Sci. 2012;118(1):33-42. doi:10.1254/jphs.11060FP

12. Filippi GM, Errico P, Santarelli R, Bagolini B, Manni E. Botulinum A toxin effects on rat jaw muscle spindles. Acta Otolaryngol. 1993;113(3):400-404. doi:10.3109/00016489309135834

13. Oh HM, Chung ME. Botulinum toxin for neuropathic pain: a review of the literature. Toxins. 2015;7(8):3127-3154. doi:10.3390/ toxins 7083127

14. Page MJ, McKenzie JE, Bossuyt PM, et al. The PRISMA 2020 statement: an updated guideline for reporting systematic reviews. BMJ. 2021;372:n71. doi:10.1136/bmj.n71
15. Higgins JP, Altman DG, Gøtzsche PC, et al. The Cochrane Collaboration's tool for assessing risk of bias in randomised trials. BMJ. 2011;343:d5928. doi:10.1136/bmj.d5928

16. Cumpston M, Li T, Page MJ, et al. Updated guidance for trusted systematic reviews: a new edition of the Cochrane Handbook for Systematic Reviews of Interventions. Cochrane Database Syst Rev. 2019;10:ED000142. doi:10.1002/14651858.ED000142

17. Higgins JP, Thompson SG. Quantifying heterogeneity in a meta-analysis. Stat Med. 2002;21(11):1539-1558. doi:10.1002/ sim. 1186

18. Egger M, Davey Smith G, Schneider M, Minder C. Bias in meta-analysis detected by a simple, graphical test. BMJ. 1997;315 (7109):629-634. doi:10.1136/bmj.315.7109.629

19. Yuan RY, Sheu JJ, Yu JM, et al. Botulinum toxin for diabetic neuropathic pain: a randomized double-blind crossover trial. Neurology. 2009;72(17):1473-1478. doi:10.1212/01.wnl.0000345968.05959.cf

20. Ghasemi M, Ansari M, Basiri K, Shaigannejad V. The effects of intradermal botulinum toxin type A injections on pain symptoms of patients with diabetic neuropathy. J Res Med Sci. 2014;19 (2):106-111.

21. Salehi H, Moussaei M, Kamiab Z, Vakilian A. The effects of botulinum toxin type A injection on pain symptoms, quality of life, and sleep quality of patients with diabetic neuropathy: a randomized double-blind clinical trial. Iran J Neurol. 2019;18(3):99-107.

22. Taheri M, Sedaghat M, Solhpour A, Rostami P, Safarpour Lima B. The effect of intradermal botulinum toxin A injections on painful diabetic polyneuropathy. Diabetes Metab Syndr. 2020;14 (6):1823-1828. doi:10.1016/j.dsx.2020.09.019

23. Bach-Rojecky L, Lacković Z. Central origin of the antinociceptive action of botulinum toxin type A. Pharmacol Biochem Behav. 2009;94(2):234-238. doi:10.1016/j.pbb.2009.08.012
Journal of Pain Research

\section{Publish your work in this journal}

The Journal of Pain Research is an international, peer reviewed, open access, online journal that welcomes laboratory and clinical findings in the fields of pain research and the prevention and management of pain. Original research, reviews, symposium reports, hypothesis formation and commentaries are all considered for publication. The manuscript management system is completely online and includes a very quick and fair peer-review system, which is all easy to use. Visit http:// www.dovepress.com/testimonials.php to read real quotes from published authors. 